\title{
Sismique en forage et diagraphies acoustiques
}

État de l'art du domaine géotechnique et transferts méthodologiques possibles du domaine pétrolier 


\section{Sismique en forage et diagraphies acoustiques}

État de l'art du domaine géotechnique et transferts méthodologiques possibles du domaine pétrolier

Jean-Luc Mari

Christophe Vergniault

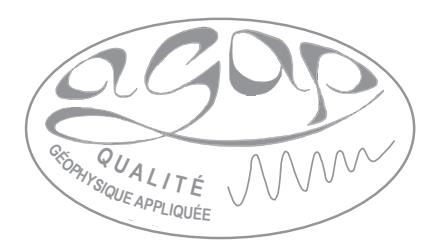

edpsciences 

DOI: $10.1051 / 978-2-7598-2262-1$

ISBN(ebook) : 978-2-7598-2262-1

Cet ouvrage est publié en Open Access sous licence creative commons CC-BY-NC-ND (https://creativecommons.org/licenses/by-nc-nd/4.0/fr/) permettant l'utilisation non commerciale, la distribution, la reproduction du texte, sur n'importe quel support, à condition de citer la source.

(C) EDP Sciences, 2018 